\title{
Cream plus Vaginal Tablet Dosage Form
}

National Cancer Institute

\section{Source}

National Cancer Institute. Cream plus Vaginal Tablet Dosage Form. NCI Thesaurus. Code C149412.

Combination package consisting of a cream and a vaginal tablet. 